\title{
Factores estresantes en los pacientes durante las sesiones de hemodiálisis
}

\author{
Andrés Moreno Rodriguez, Lourdes Benitez Ruiz, Rosa Sanz García
}

Hospital Universitario Puerta del Mar. Cadiz

\section{Objetivos:}

Conocer los factores estresantes de los pacientes durante las sesiones de hemodiálisis.

\section{Material y método:}

Diseño: Estudio prospectivo y descriptivo.

Ámbito: Unidad de hemodiálisis de un hospital universitario de referencia.

Periodo de estudio: Año 2012.

Sujetos: Pacientes con insuficiencia renal crónica en hemodiálisis.

Protocolo: Recogida durante la sesión de hemodiálisis.

Variables: Las constitutivas de la Escala de Ballard, sexo, edad, tiempo en hemodiálisis

\section{Resultados:}

Se entrevistaron 32 pacientes. El 56,3\% eran hombres y el 43,7\% mujeres. Edad media: 64 (34-87) años. Tiempo medio en diálisis 22,4 (3 -108) meses Utilizan trasporte sanitario el $90,6 \%$ de los pacientes. El $97 \%$ precisan 3 sesiones de hemodiálisis. Con movilidad autónoma el 97\%. Trasplantados previamente el $10 \%$ de los entrevistados. Los factores más estresantes fueron: Que le realicen pruebas y manipulaciones molestas y dolorosas $34,5 \%$. Dificultad/Imposibilidad para dormir $34,5 \%$. Tener mucho calor o frío $31,2 \%$. Presencia de olores extraños 37,5\%. Los factores menos estresantes fueron: Que no te acompañe ningún familiar cercano 9,5\%. No entender algunas explicaciones de las enfermeras $15,5 \%$ Falta de intimidad $18,5 \%$.

\section{Discusión:}

En nuestra unidad casi el $40 \%$ de los pacientes manifiestan su malestar por los olores extraños que perciben durante la hemodiálisis. A más de una tercera parte les genera ansiedad que le realicen pruebas y manipulaciones molestas y dolorosas, así como la dificultad o imposibilidad de conciliar el sueño y los cambios de temperatura. En contraposición más del $80 \%$ valoran muy positivamente la comunicación con el personal de enfermería, el respeto a su intimidad y el hecho de no necesitar a ningún familiar durante la sesión.

\section{Palabras clave: Intimidad, Diálisis, Dolor.}

\section{Referencias Bibliográficas}

1. BALLARD. Factores ambientales estresantes percibidos por los pacientes de una Unidad de Cuidados Intensivos Ayllón Garrido, N; Álvarez González, M; González García, M Publicado en Enferm Intensiva. 2007;18:159-67.

2. Vol.18 núm 04 Emotional disorders and psychological needs of patients in an Intensive Care Unit Med. Intensiva v.31 n.6 Madrid ago.-sep. 2007P Gómez-Carretero A, V Monsalve B, JF Soriano C, $\mathrm{J}$ de Andrés D. 